\title{
An Interactive Perspective of Health Education for the Tropical Disease Control: the Schistosomiasis Case
}

\author{
Virgínia T Schall \\ Laboratório de Educação em Ambiente e Saúde, Departamento de Biologia, Instituto Oswaldo Cruz, \\ Av. Brasil 4365, 21045-900 Rio de Janeiro, RJ, Brasil
}

\begin{abstract}
Some municipalities in Brazil have been requesting orientation for the implementation of health education programs related to the control of schistosomiasis. This demand was based on experiences in the development of health education researches, strategies and materials for school-age children, involving the communities and secretaries of health and education. Motivated by this request and the recently implemented plan of health services (Unified Health System - Sistema Único de Saúde - SUS) that gives autonomy to the municipalities to utilize health resources and services in Brazil, this paper presents an interactive perspective of planning health education research and programs. The purpose of this perspective is to stimulate a reflection on the needs and actions of institutions and people involved in health education research and/or programs to obtain sustainability, commitment and effectiveness not only in the control of schistosomiasis, but also in the improvement of environmental conditions, quality of life and personal health. This perspective comprises interaction among three levels related to health education programs: the decision level, the executive level and the beneficiary level. The needs and lines of action at each of these levels are discussed, as well as the ways in which they can interact with each other. This proposal may lead to useful interactive ways of planing, organizing, executing and evaluating health education research and/or program, not only towards the prevention and control of the disease at stake, but also to promote health in general.
\end{abstract}

Key words: health education - schistosomiasis

Recent reports from the World Health Organization (WHO 1993, 1995) state that the control of schistosomiasis has to be an integrated effort which includes methodologies and managerial tools to improve preventive strategies, and emphasizes health education, information and communication. This should be achieved by using the primary health care approach, mainly in endemic areas deprived of basic sanitation (Kloos 1995). Since the late 50's, the importance of combined control measures, which include health education, was referred to as essential for the successful control of schistosomiasis (Hollanda 1958, MacDonald 1965, Garcia 1966, Sandbach 1975, Schall 1987, 1995, Kloos 1995). However, few experiences succeeded in integrating socio-cultural, economic and educational frameworks to promote awareness, prevention and control of the disease (Dunn 1979, Huang \& Maderson 1992, Kloos et al. 1993, Kloos 1995). Further efforts are required towards the improvement of preventive action and effective evaluation

Received 4 May 1998

Accepted 31 August 1998 measures. This paper intends to demonstrate the role and possible applications of health education in the integrated control of schistosomiasis. It also proposes a simple way to identify and plan the needs and actions for each level of participation involved in a research project or in a control program.

CONTROL OF SCHISTOSOMIASIS AND HEALTH EDUCATION: A SHORT PARALLEL

Establishing a parallel between the evolution of measures of schistosomiasis control and the specific field of health education, it is noteworthy that, in the course of this century, the methodologies have been transformed, superseding the paradigm of medical and biological sciences, incorporating the methodologies of social and human sciences (Glanz et al. 1990).

Concerning the control of shistosomiasis, the focus used to be restricted to vector control until approximately the first half of this century. Until then, the drugs developed for human treatment were difficult to administer and had serious side effects. Following the development of new effective drugs and diagnostic techniques in the 70's, emphasis on vector control was replaced by the control of morbidity through patient treatment. At that time, some authors were already recommending strategies of 
integrated control. They suggested multiple associated measures, which included control of vectors, treatment of patients, as well as environmental improvements, basic sanitation and health education (Hollanda 1958, MacDonald 1965, Garcia 1966, Sandbach 1975). During the last two decades (80 and 90), some experiments were reported as being initiatives of integrated control. However, many of those experiments failed since the beliefs, attitudes, behavioral patterns, knowledge and misconceptions of local populations and ecological features inherent to each environment were not taken into consideration (Huang \& Manderson 1992, Kloos 1995). These features yielded considerable variations in the epidemiology of schistosomiasis (Huang \& Manderson 1992). In addition, up to a certain point, the paradigm of epidemiology becomes insufficient and calls for methodologies used in social and human sciences, as was reported by Huang and Manderson (1992), Kloos (1995) and Schall (1995). Since the 80s, the knowledge of peculiar factors related to schistosomiasis has been discussed through the study of economic, social and behavioral variables of the disease. However, according to Huang and Manderson (1992), water contact and socioeconomic studies drew little academic attention and sometimes being one-sided, focused on a sole variable and would call for larger investment in the field. On the other hand, cultural studies on schistosomiasis are amazingly rare.

Officially established in 1919 at an American Childhood International Conference (Melo 1987), the health education field tended to emphasise health as an individual responsibility. Only much later, this area has included socioeconomic and cultural variables (Briceño-Leon 1996). As well as epidemiology, health education was influenced by social medicine that created a macro framework for understanding the process of health and disease (Barata 1997). The social medicine movement generated in industrialized Europe was anchored in some landmarks including: the health of the population is a social responsibility, economic and social conditions have important consequences to health and disease. Thus, health and disease are viewed as aspects of the social structure which require social and medical measures to promote health and disease control. In this way, health sciences are given an 'ethical' connotation necessary to overcome the gaps among social classes (Barata 1997). With this macro framework, the biological agents of the diseases became understood as necessary but not sufficient to cause a disease, since they are dependent on other factors to lead to functional morphological alterations and disease. Therefore, preventive and control measures that are restricted to eliminate the biological agents often become unsuccessfully because they require educational investment and socio and economic improvements.

In this way, we observe a change in methods and strategies concerning research and programs which comprise health education, superseding emphasis on the individual and discussing the importance of dealing with the variables that account for the social incidence of the disease. From this perspective, health education has to stimulate community participation and it is necessary to have knowledge of individuals and their living circumstances in order to take efficient action in health, promoting individual responsibility and collective cooperation, as pointed out by Briceño-Leon (1996). Such orientation requires an investment in studies that establish a better comprehension of human beings and their relationships, which include psychological and affective investigations associated with the necessary knowledge concerning the specific socio-economic and cultural aspects related to health (Schall 1996). However, focusing specifically on schistosomiasis, only recently have the methodologies of social sciences been used in the process of investigation (Kloos et al. 1987, Schall 1987, Patwari \& Aneja 1988, Rozemberg 1994, Barbosa 1996).

\section{THE OBJECTIVES OF HEALTH EDUCATION WITHIN THE FRAMEWORK OF AN INTEGRATED PROGRAM OF SCHISTOSOMIASIS CONTROL}

If we consider the influence of socioeconomic, cultural and geographical factors on how schistosomiasis prevails, intensifies and perpetuates, the researcher or technician committed to health education has a fundamental role in integrated control programs. He/she can be the professional who promotes interaction among specialists of different study areas, thus encouraging an integrated control program. This professional shall be present during the planning of research and programs, encouraging a wide-ranging local diagnosis of the variables associated with the risks of contamination. These variables shall include age, sex, religion and occupation, focusing on their relation to behaviors such as: (1) exposure and contact with water, specifying whether its use is domestic or for pleasure as well as religious practice and subsistence work (2); behavioral pattern of transmission; (3) compliance or resistance to measures of prevention and/or treatment; (4) economic impact of the work, (5) knowledge and beliefs regarding items 1 to 4 .

Thus, the health educator shall encourage shared planing between the technical staff involved in the research or program, community members and political leaders, in order to attain the following objectives: 
- clarify concepts and methodologies regarding the role played by human behavior in the transmission and control of the disease, including the discussion of the health concept, focusing on the social, mental/emotional and physics aspects and the importance of health promotion;

- provide assistance in the planning, execution and assessment of lines of action, based upon an awareness of specific ecological conditions and diversity related to each endemic area;

- encourage local government and communities to take part in the planning and development of control programs by using local resources in order to improve sanitation and/or taking other necessary measures;

- provide assistance and cooperation in vector control programs as well as implementing preventive measures and compliance with parasitological examinations and treatment, encouraging local communities to take part in these projects;

- use entertainment and cultural resources so as to promote reflection as well as individual and collective commitment along with participation in environmental improvements;

- encourage a build-up of knowledge and behavior modification so as to reduce the risks of contamination and exposure, taking into account local beliefs, thus avoiding being confined to explanations based only in a medical model;

- encourage communities motivation in order to keep up with programs and increase self-confidence in health-related activities.

Most health education and shistosomiasis control programs failed by regarding the intrinsic feature of each individual case, since such knowledge is insufficient with respect to the inherent aspects of affected communities and their divergent logic (Kloetzel 1989). As Kloos (1995) warned, "an educational method shall be effective solely if it suits the local conditions where it is applied". Moreover, there is an inherent tendency to blame the individual at risk instead of understanding the social conditions that favors the disease. What is commonly observed is a number of projects in which priority is not given to specific disease control, this being the case for both communities and health authorities, combined with the inefficiency of public health services and lack of political and community participation (Rosenfield 1990).

BELIEFS AND ATTITUDES RELATED TO SCHISTOSOMIASIS THAT MAY CAUSE DIFFICULTIES IN THE IMPLEMENTATION OF CONTROL PROGRAMS

Success in health education along with community participation is influenced by knowledge and the perception of the disease, how it is transmitted, the way symptoms occur and their degree of gravity. A large number of studies reported the difficulties of control associated with the diversity of interpretation of the disease and the peculiar models to deal with it. An extensive revision by Kloos (1995) comprises information from research done in many parts of the World, notably in Kenya and Tanzania where ethnic groups associate dermatitis caused by cercariae as a result of water contact. They tend to favor treatment at home by using various medicinal plants to treat cases of hematuria (S. haematobium) and intestinal disorder (S. mansoni) and thus do not resort to medical treatment (Kloos et al. 1987). In Cameroon, people from rural areas used to relate hematuria to excessive exposure to sunlight and sexual intercourse, dismissing medical treatment in local hospitals as a result of such beliefs (Robert et al. 1989). In Nigeria, infected women believed that $S$. haemetobium was sexually transmissible, and as a result did not consult a physician for fear of being expelled from home by their husbands (Vogel 1992). In southeast Brazil, the name given to the disease: 'snail disease' leads to the belief that the snail itself enters the human body, and this belief acting as an overwhelming influence diverts popular attention from the role played by human faeces in the transmission (Rozemberg 1994). Religious beliefs can also be the source of secular behaviors and are not likely to be dismissed since they are rooted within traditional cultures. Arabia is such an example, were there is a permanent residual percentage of $1 \%$ of schistosomiasis prevalence associated to a few Muslim communities with peculiar customs. According to Rey (1997), in these communities the habit of having picnics is widespread and people use to take bath after urination or defecation near the picnic sites. They have to wash themselves in flowing water (which is mandatory for religious reasons). This custom ends up causing the contamination of natural watercourses and contributes to the maintenance of schistosomiasis. This behavior was also observed by Farroq and Nallat (1966). Besides popular creeds there is also the problem of turning information into preventive behavior in places where environmental improvements do not always keep up with educational measures.

Surveys performed in Egypt with young students and adults have shown they had good information on schistosomiasis. Despite the fact they knew they had to avoid being exposed to contaminated water, exposure was occurring for lack of other alternatives (Kloos 1993). The same situation occurred in northeast Brazil, where a major attempt to implement an integrated program of control failed because of delayed funding and through not taking concomitant measures of education and 
sanitation. Consequently, information on the disease caused what Coutinho and Pimont (1981) called cognitive dissonance, since individuals were not in possession of means to avoid contact with the water that caused the disease. They remained exposed to the water, despite being aware of the threat to their health.

Information can be basic for the decision about seeking or not a treatment. In Malasia, awareness of the seriousness of the disease along with infection control was correlated to compliance towards control measures (Ager 1992). In the Philipines, those people less well informed about schistosomiasis were more afraid of the disease and took more drastic measures to prevent infection than others (Herrin 1988). In Brazil, people from rural endemic areas showed disbelief in the clinical explanations that a tiny worm could penetrate the body through the skin and even when accepting this hypothesis, most people kept the belief that the worm could also be swallowed with drinking water. As a result, families felt protected by avoiding drinking water directly from streams but were stepping continuously into contaminated water, were being continually reinfected (Schall 1995, Rozemberg 1995, Barbosa 1996). There is also the fact that shistosomiasis is considered a minor disease by many communities when compared with poverty, starvation and lack of basic needs such as schools, electricity, roads and employment (Kloos 1995). Morbidity studies have shown that in some endemic communities, shistosomiasis is rarely considered a major health issue. These communities end up living with the symptoms (Rozemberg 1994).

\section{HEALTH EDUCATION MODELS}

Applying knowledge of health education to the control of schistosomiasis requires from educators the establishment of a conceptual and philosophical basis that may be flexible and readily adaptable to the various ecological conditions of transmission, taking into account the cultural features of the communities from endemic areas. There is more than just one philosophical standpoint or practical orientation that may be applied to all situations arising in health education - thus, the challenge for the health educator is to understand the principles of educational processes and how such principles may effectively be applied to each particular situation. Although this paper does not intend to be an in-depth discussion of the theoretical principles that provide a basis of health education, the purpose is to outline a synthesis with respect to models that enable practical lines of action and to discuss how they can be applied to the control of schistosomiasis. Bedworth and Bedworth (1992) presented some of the models to be applied in health education, based upon learning principles of psychology and from the theory of communication and sociology.

The models that focus on the health behavior of the individual are based on intrapersonal theories emphasizing the expectations and lay explanatory models about health and diseases. One of them, the health belief model, assumes that an individual has the capacity to change his/her behavior by focusing on the cognition and motivation processes. Health education actions based on this orientation are often criticized as unrealistic, especially in the case of schistosomiasis control, which requires taking into account both social and economic factors which are involved in the disease, as pointed out by Kloos (1995). Another model based on this micro approach, is called Consumer Information Process, and focuses on how individuals use information for health education, as the aspect to be considered in a research or program.

Other models focus on the interpersonal health behavior and pay attention on how individuals interact in their environments. Interpersonal models are based on the social learning theory, the purpose of which is to understand how individuals and environment interact to influence the health behavior. One model called "patient-provider interaction and health care" tries to understand the health professionals' influence on the health behavior of the population as well as to develop practices to promote behavioral changes through interactive situations.

Another group of models are called intervention models of health behavior change. These models are based on theories of organizational changes and search to improve health through: (1) community organization, (2) mobilization of health organizations, or (3) mass communication. In the extensive review of Kloos (1995) about human behavior, health education and schistosomiasis control, the author gives examples of the applicability of some models on the control of shistosomiasis, including one from Brazil (Schall 1987, "empowering education model") and another from Egypt (Loza 1993, "social marketing model"). The author also suggests the possibility of reaching the middle ground between the opposite models that focus on the individual (micro view) or on the system (macro perspective). Kloos recommends the "community", as the optimal point of intervention, integrating the person and the environment to health promotion, incorporating regional and national factors and considering the socioeconomic and cultural context that influences behavior. Kloos (1995) also presents a very useful model (PRECEDE model), adapted from a Green model which 
allows the establishment of a detailed diagnosis of schistosomiasis, including educational, behavioral, epidemiological and social diagnosis. Using this model, it is possible to identify the 'predisposing', 'enabling' and 'reinforcing' factors related to vulnerability to the disease, the behavioral problems that contribute to the transmission and reinfection, and the health and the social problems related to the maintenance of the disease. This model is an important educational framework to develop an extensive diagnosis in order to reach an integrated model to control of schistosomiasis, that can show a new awareness to the role of the human perceptions, attitudes and behavior related to the disease. It can also help to develop more effective strategies of action appropriate to the local needs and resources.

\section{THE INTERACTIVE PERSPECTIVE - A PROPOSAL}

Although the literature presents data and examples of the possible ways in which to develop an integrated means of schistosomiasis control, there are several difficulties that have to be considered, ranging from the viewpoint of the political decision that plan the policies and resources allocated to health researches and programs through to the problem of sustaining community participation. The necessary integration is presented here (Figure) including three levels: the decision level, (DL) the executive level (EL) and the beneficiary level (BL). The decision level refers to the national and international organizations and agencies that make the health policies and give the financial support to research and/or programs. Considering a historical perspective the DL can select some aspects and strategies and ostracize others, according to the current political orientation and dominant subjects in the scientific area.

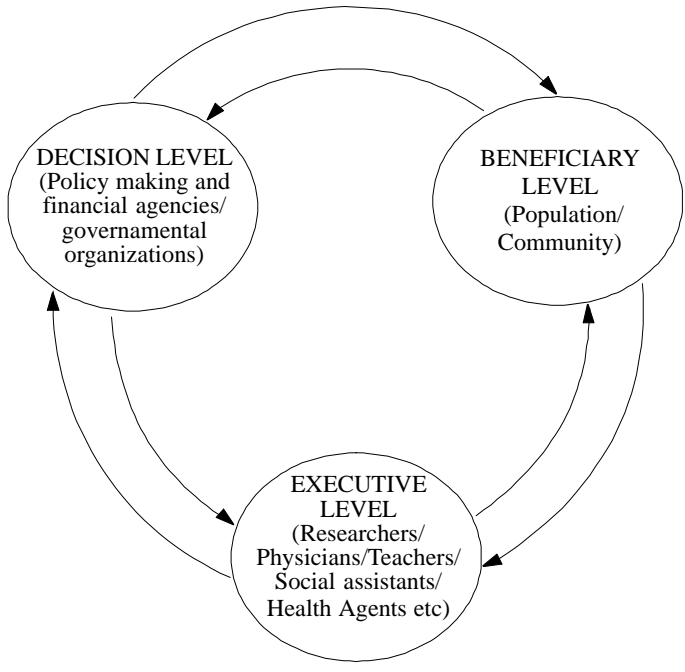

An interactive model of health education including the needs and actions of the principal levels involved in tropical disease control.

In the last years, although health education has been receiving more attention, this area never received the necessary incentive and resources from DL. Table I presents a summary of some requirements and actions referred to the DL in order to reach more cooperation from this level with the health education area in the diseases' control research and/ or program.

The EL includes the staff that plans, executes and evaluates the research and/or programs, as researchers, physicians, teachers, health agents etc. Table II shows the requeriments and actions of the EL, considering the importance of establishing a better integration among them and intensify the interaction with the other levels.

\section{TABLE I}

Needs and actions of the Decision Level (DL) - (Policy making and financial agencies/ Governamental organizations)

NEEDS

- DL should ask and receive information from researchers about the needs to perform the studies and new control measures.

- DL should ask and receive information about the priority needs in the field as:

(a) the needs of endemic communities;

(b) the needs of the researchers and technical staffs to execute the control programs.
ACTIONS

- DL should give information about its orientation.

- DL should evaluate the opinion of the scientific community about the proposed changes.

- DL should create a data center of health education/ communication/ research/materials/etc.

- DL should publish and divulgate a review (book) with the well-succeeded experiences/ programs.

- DL should recommend the inclusion of a social scientist in the studies where community is involved.

- DL should stimulate or organize courses/seminars about health education/communication.

- DL should create committees shared by persons from the executive level and beneficiary level. 
The BL is characterized by the population and/ or communities involved in the research and/or programs. Table III presents the requeriments and actions of this level, which has to participate in the process of health promotion and in the control of specific diseases. The needs and actions suggested in each table could be a starting point for reflections on the role and responsibilities of each level in disease control programs. This exercise can provide opportunities to clarify possibilities, difficulties and limits present in specific situations, in order to develop a better plan for disease control and health promotion. For each different population/ community, it may be necessary to include other needs and actions, more specific to the conditions identified through previous diagnosis.

\section{DISCUSSION}

According to the three literature reviews made by Huang and Manderson (1992), Kloos (1995) and Schall (1995) on the topic of health education research and/or programs on social and economic aspects related to schistosomiasis, very little research has been carried out on these subjects. The majority of the studies performed, mainly in Africa, Asia and Brazil, suggested the demand of in- tegration between the social and educational dimension in research and/or programs of schistosomiasis control. Great part of these studies stressed that health education strategies integrated in control programs have a higher chance of success when they are planned and implemented with the participation of the three levels involved. Such a strategy would require that persons from the DL, EL and BL participate in planning the program schedules, which means that the government sector cooperates with the education and health sectors who in turn encourage the community participation in the planning and execution of the activities. Although the importance of health education is well recognized, most studies performed to date have not provided a systematic evaluation process of their achievements. It is necessary to measure not only changes in knowledge or short-term behavior, but also permanent effects on specific risk behaviors related to exposure to and transmission of a disease, as well as improvements in health, environment, and general life quality.

Since the Alma-Ata Conference (WHO 1978), active community participation in the health education processes and in programs of diseases control has been stimulated by WHO. Participatory

TABLE II

Needs and actions of the Executive Level (EL) - (Researchers/Teachers/Health agents)

\section{NEEDS}

- EL should recognize the importance of health education/communication in the schistosomiasis control.

- EL should receive support to include health education in the researchs and programs.

ACTIONS

- EL should include health education/communication to identify the problems and needs of communities and control programs.

- EL should create new strategies/materials evaluation methods.

- EL should promote broadcasting of the information.

- EL should stimulate reflections about the relation: health $\mathrm{x}$ life conditions.

- EL should involve the communities in the control programs as well as the local authorities.

- EL should exercise a surveillance and criticism about the socio-politic economical interests and possible inadequate use of the researches/programs.

\section{TABLE III}

Needs and actions of the Beneficiary Level (BL) - (Communities/Population)

\begin{tabular}{|c|c|}
\hline NEEDS & ACTIONS \\
\hline $\begin{array}{l}\text { - BL should receive information about the health } \\
\text { problems. } \\
\text { - BL should receive support and orientation to participate } \\
\text { in the control programs. } \\
\text { - BL should develop ways of sustaining the health } \\
\text { programs } \\
\text { - BL should have access to the health services and } \\
\text { reasonable environmental conditions. }\end{array}$ & $\begin{array}{l}\text { - BL should collaborate/participate in the control } \\
\text { programs. } \\
\text { - BL should exercise a surveillance and criticism about } \\
\text { the programs implemented. } \\
\text { - BL should collaborate in broadcasting the information. } \\
\text { - BL should create cultural means/materials of } \\
\text { information. }\end{array}$ \\
\hline
\end{tabular}


education implies not only the active involvement of the community members in the learning process, but also the commitment of the local government authorities and the staff that coordinates the research and/or program. In reality, these recommendations are present in theory, being rarely put into practice. The conclusions referred in the WHO report on schistosomiais (1993), recommend that health education should be included in all endemic countries. Focusing on individual hygiene and behavior, but calling attention to the importance of community participation in the process of prevention and control, WHO reports present few experiences towards health education integrated in disease control, reflecting the small numbers of studies reported in the literature.

Considering the variability and specificity of schistosomiasis' expression in each community, in each of them, diagnosis, planning, execution and evaluation of the activities or studies could be improved if this process is shared by persons from each local level involved. This is a kind of exercise to do together, trying to achieve improved comprehension and effectiveness in prevention and control actions. It should also include evaluation measures that can provide better information on the impact of schistosomiasis in the communities and the possible changes that can be associated with the planned interventions.

In Brazil, there are abrupt changes in health policies and recently the responsibilities of the health services were transferred from the federal to the municipal level. Although this new perspective is much more adequate to the requirements of the country, in a short time, this change promoted short-term discontinuity in some programs under development and had serious consequences to the health area. In the case of schistosomiasis, in some localities, the absence of municipal trained personnel to do the surveillance of the disease resulted in populational growth of the snail vector and higher prevalence. There is a need to think about a gradual change with appropriate training strategies to the municipal personnel, in order to promote commitment for the municipal control of disease in the endemic areas. In this perspective, it is very important to foster a dialog among all levels involved in the health services provided by the primary health-care system, addressing the issues that require a significant technical imput. The interaction among the health educators and the medical personnel implies an awareness that the education process offers a broad opportunity to obtain the most efficient results in the control of diseases and in general health promotion.

It is also important to create special situations or special sections to ask community members in- volved in the programs of disease control to present their experiences in scientific and pedagogic meetings and workshops, exchanging that knowledge and becoming more motivated through the recognition and valorization of their work.

Promoting and coordinating the interaction among the three levels involved in the prevention and control of schistosomiasis, the EL can improve both political and social sensitivity towards disease control and thus help to provide a wide range of health benefits to all. The interactive perspective presented here are intended to stimulate this challenge.

\section{ACKNOWLEDGEMENTS}

To Dr Isabela Cabral Felix Sousa and Dr Brani Rozemberg for english review and valuable comments.

\section{REFERENCES}

Ager A 1992. Perception of risk for malaria and schistosomiasis in rural Malawi. Trop Med Parasit 43: 234-238.

Barata R 1997. Causalidade e epidemiologia. Manguinhos: História, Ciência e Saúde 4: 31-49.

Bedworth AE, Bedworth DA 1992. The Profession and Practice of Health Education. Wm. C. Brown Publishers, Dubuque. 472 pp.

Barbosa CGS 1996. Esquistossomose em Pernambuco: Determinantes Bio-ecológicos e Sócio-culturais em comunidade de Pequenos Agricultores da Zona da Mata. PhD Thesis. Escola Nacional de Saúde Pública, Fiocruz, Rio de Janeiro. 148 pp.

Briceño-Leon R 1996. Siete tesis sobre la educación sanitaria para la participación comunitaria. Cad Saúde Púb 12: 7-30.

Coutinho LM, Pimont RP 1981. Educação em saúde e comunicação de massa numa experiência concreta no combate da esquistossomose. Tecnol Educ 10: 47-52.

Dunn FL 1979. Behavioural aspects of the control of parasitic diseases. Bull WHO 57: 499.

Farooq M, Nallah J 1966. The behavioural pattern of social and religious water-contact activities in the Egypt-49 bilharziasis project area. Bull WHO 35: 377-387.

Garcia ALR 1966. Educação sanitária e esquistossomose. Rev Bras Malar Doenç Trop 17: 175-188.

Glanz K, Lewis FM, Rimer BK 1990. The scope of health education: parameters of a maturing field. In Glanz et al. (eds), Health Behavior and Health Education. Jossey-Bass Publishers, San Francisco. 460 pp.

Herrin AN 1988. Perceptions of disease impacts: what can they tell us? p. 225-232. In AN Herrin, AL Rosenfield (eds), Economics, Health and Tropical Diseases. University of the Philippines, School of Economics, Manila.

Hollanda H 1958. A contribuição da educação sanitária no controle da esquistossomose e outras parasitoses e seu papel no desenvolvimento das comunidades. p. 546-547. Proceedings of the VI International Congress on Tropical Medicine and Malaria. 
Huang Y, Manderson L 1992. Shistosomiasis and the social patterning of infection. Acta Tropica 51: 175194.

Kloetzel K 1989. Schistosomiasis in Brazil: does social development suffice? Parasitol Today 5: 388-391.

Kloos H 1985. Water resoucers development and shistosomiasis ecology in the Awash Valley, Ethiopia. Soc Sci Med 20: 609-625.

Kloos H 1995. Human behavior, health education and schistosomiasis control: a review. Soc Sci Med 40: 1497-1511.Kloos H, Higashi GI, Cattani JA, Schlinski VD, Mansour NS, Murrell KD 1983. Water contact behavior and shistosomiasis in na upper Eyptian village. Soc Sci Med 17: 545-562.

Kloos H, Ouma JH, Kariuki HC, Butterworth AE 1987. Coping with intestinal illness among the Kamba of Machakos, Kenya, and aspects of shistosomiasis control. Soc Sci Med 24: 383-394.

Loza S 1993. Health education, mass media and schistosomiasis operations research results. p. 41. Abstracts of the S.R.P. 1993, International Conference on schistosomiasis, Shistosomiasis Research Project. Ministry of Health, Cairo.

MacDonald G 1965. The dynamics of helminth infection, with special reference to schistosomiasis. Trans $R$ Soc Trop Med Hyg 59: 489-506.

Mello JAC 1987. Educação sanitária: uma visão crítica. p. 28-43. Cadernos do CEDES/ Educação em Saúde (4), Cortez Ed., São Paulo.

Patwari AK, Aneja S 1988. Urinary schistosomiasis in schoolchildren. Tropical Doctor 18: 1-4.

Rey L 1997. Conference about schistosomiasis control. Centro de Estudos do Instituto Oswaldo Cruz. Fundação Oswaldo Cruz, Rio de Janeiro.
Robert CF, Bouvier S, Rougemont A 1989. Epidemiology, anthropology and health education. Wld Hlth Forum 10: 355-364.

Rosenfield PL 1990. Social determinants of tropical disease, p. 197-205. In KS Warren, AAF Mahmoud (eds). Tropical and Geographycal Medicine, McGraw-Hill, New York.

Rozemberg B 1994. Representações sociais de eventos somáticos ligados à esquistossomose. Cad Saúde Púb 10: $30-46$.

Rozemberg B 1995. A Intransparência da comunicação: Crítica Teórico Metodológica sobre a Interação entre o Saber e as Práticas Médicas e a Experiência das Populações de Áreas Endêmicas de Esquistossomose. PhD Tesis. Escola Nacional de Saúde Pública, Fiocruz, Rio de Janeiro. 147 pp.

Schall VT 1987 Health education for children in the control of shistosomiasis. Mem Inst Oswaldo Cruz 82 (Suppl. IV): 285-295.

Schall VT 1995. Health education, public information, and communication in schistosomiasis control in Brazil: a brief retrospective and perspectives. $\mathrm{Mem}$ Inst Oswaldo Cruz 90: 229-234.

Sandbach FR 1975. Preventing schistosomiasis: a critical assessment of present policy. Sci Med 9: 517-527.

WHO-World Health Organization 1978. Report of the International Conference on Primary Health Care, Alma-Ata. Health for all Series, 1, $79 \mathrm{pp}$.

WHO-World Health Organization 1993. The Control of Schistosomiasis. Technical Report Series 830, Geneva. 86 pp.

WHO-World Health Organization 1995. Tropical Disease Research Progress 1975-1994. Technical Report Series. Geneva. 167 pp. 